Sergio Alexandre GEHRKE(a) Jamil Awad SHIBLI(b) Jaime Sardá ARAMBURÚ JUNIOR(a) José Eduardo Maté Sánchez de VAL (c) José Luis CALVO-GIRARDO(c) Berenice Anina DEDAVID(d)

(a) Universidad Católica San Antonio de Murcia - UCAM, Department of Biotechnology, Murcia, Spain.

(b) Universidade de Guarulhos, Division of Dental Research, Department of Periodontology and Oral Implantology, Guarulhos, SP, Brazil.

(c) Universidad Católica San Antonio de Murcia - UCAM, International Dentistry Research, Murcia, Spain.

(d) Pontifícia Universidade Católica do Rio Grande do Sul - PUC-RS, School of Dentitry, Department of Materials Engineering, Porto Alegre, RS, Brazil.

\section{Effects of different torque levels on the implant-abutment interface in a conical internal connection}

\begin{abstract}
The fit of the implant-abutment interface was assessed by the metallographic technique and by scanning electron microscopy (SEM), using solid abutment types at different torque levels. Forty Morse taper connections and forty solid abutments were used at different torque levels (repeated after 10 minutes) in the following groups $(\mathrm{n}=10)$ : $25 \mathrm{Ncm}$ (group g1), $30 \mathrm{Ncm}$ (group g2), $35 \mathrm{Ncm}$ (group g3), and $40 \mathrm{Ncm}$ (group g4). The samples were embedded in a metallographic resin, sectioned lengthwise, and polished. SEM images were used to measure the linear contacts and the fits between abutments and the internal walls of the implant. The overall mean gap and standard deviation were as follows: $9.0 \pm 1.36 \mu \mathrm{m}$ for group g1, $7.9 \pm 2.81 \mu \mathrm{m}$ for group g2, $2.0 \pm 0.76 \mu \mathrm{m}$ for group g3, and $0.3 \pm 0.40 \mu \mathrm{m}$ for group g4. A significant difference was observed in the average fit values between the groups $(p<0.05)$. The linear area of contact between the abutment and the implant increased as torque augmented. This study demonstrated that higher insertion torque values in a conical internal connection increase the fit (contact) of the implant-abutment interface.
\end{abstract}

Keywords: Dental Implants; Dental Abutment; Dental Implant-Abutment Interface.

\section{Introduction}

Dental implants have been used extensively in oral rehabilitation for the replacement of one or more missing teeth with satisfactory survival rates. ${ }^{1,2,3}$ However, adverse biological responses and prosthetic restoration complications can occur. The stability of the implant-abutment interface is an important factor that influences load distribution to the marginal bone. The most frequent complications arising from misfits of the implant-abutment interface include: a) biological complications that include increased load transfer to the bone, bone loss, and development of microflora in the micro-gap between implant and abutment $\mathrm{t}^{4,5,6}$ and b) prosthetic complications that include screw loosening or fracture and implant loss.7

Due to the absence of a periodontal ligament, implants are incapable of readily adapting to stresses caused by poorly fitted restorations. ${ }^{8}$ Micro-gaps can form in the abutment/implant interface due to loose abutment fixtures, thus favouring bacterial invasion and mechanical problems. ${ }^{9}$ In every implant system, the efficiency of the fixture joint system depends on several factors, such as component design, connection 
geometry between implant and abutment, mechanical adjustment between the fixture and its set surface on the abutment, mechanical and physical component properties, and torque application. ${ }^{10}$

Fixture joint system efficiency can be improved by taking the screw off and subsequently tightening it. ${ }^{11,12}$ During abutment screw tightening, a compressive strength is generated to keep implant and abutment surfaces in contact. The success of this joint is directly related to attaining preload during its tightening and maintaining this preload over time. Fixture loosening and critical preload reductions can compromise joint stability and maximize the likelihood of clinical failure. ${ }^{13}$

Regarding screw tightening, several authors have reported that increasing the torque applied to the screws also increases the compression between the contacting surfaces and provides greater stability to the joint.$^{14}$ Given the long-term successful follow-ups of Morse taper implants, ${ }^{15,16}$ this study aimed to evaluate the torque level related to the fit of the implant-abutment interface.

\section{Methodology}

A total of 40 dental implants with conical internal connection at an 11-degree wall inclination, $4 \mathrm{~mm}$ in diameter and $11 \mathrm{~mm}$ in length, and 40 straight solid abutments with the dimensions and characteristics shown in Figure 1 were used. The implants were clamped to the equipment, and the 40 abutments were placed on the implants. Different torque levels were applied with a torque testing machine - CME (Técnica Industrial Oswaldo Filizola, Guarulhos, Brazil), fully controlled by the DynaView Torque Standard/Pro M software (Figure 2) which performed the calculations and generated reports automatically. A test speed of $1 \mathrm{rpm}$ and an angle measuring system with a resolution of $0.002^{\circ}$ were used to determine the groups ( $\mathrm{n}=10$ in each group) as follows: group 1 (g1), $25 \mathrm{Ncm}$ torque; group 2 (g2), $30 \mathrm{Ncm}$ torque; group 3 (g3), $35 \mathrm{Ncm}$ torque; and group 4 (g4), 40 $\mathrm{Ncm}$ torque. As reported in other studies, to limit the effect of sedimentation on the screws, which leads to preload reductions, the components were retightened with the respective torque values 10 minutes after the initial torque was applied. ${ }^{17}$

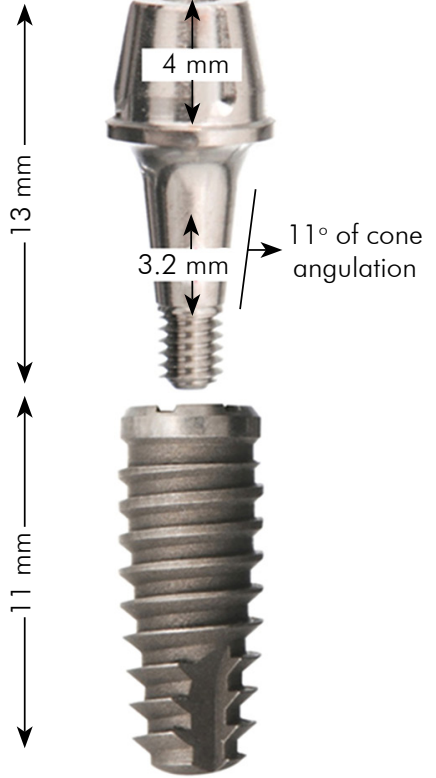

Figure 1. Image showing the characteristics of the implant and abutment used in this study.

Next, all samples were embedded in metallographic epoxy resin (Geotec Minerologia, São Paulo, Brazil) and sectioned with a diamond disc in a metallographic cutter (Isomet 1000, Buehler, Haan, Germany) to yield cuts at the center of the longitudinal joints (Figure 3). The slices were then polished in a mechanized machine (Polipan-2, Pantec, São Paulo, Brazil) using a sequence of abrasive papers to obtain good surface smoothness. Next, the samples were placed in an ultrasonic tank, washed, dried, and metalized with gold (Sputter Coater BAL-TEC SCD 050, New York, USA).

The samples were analyzed under a scanning electron microscope (SEM; model XL30, Philips, Eindhoven, Netherlands) via a series of images taken in the secondary electron (SE) mode. Data collection was performed in six positions defined as A, B, C, D, $\mathrm{E}$ and $\mathrm{F}$ (Figure 4a). Three measures (L1, L2 and L3) were obtained from each picture at a magnification of $5000 \mathrm{x}$; the first one from the center (L2), and the other two $10 \mu \mathrm{m}$ away from the first; and averages were generated for each position (Figure $4 b$ ).

The possibility of contact between abutment and implant have a linear extension of $3.2 \mathrm{~mm}$, and for the analysis of the extent of contact in each group, this space was divided schematically into two parts on each side of the image, generating four positions 


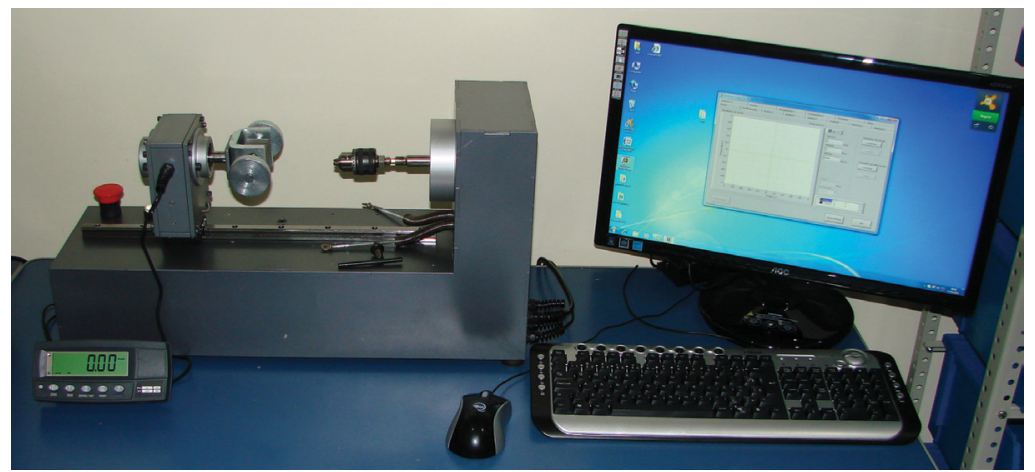

Figure 2. Image of the computer-aided torque test machine used for the measurements.

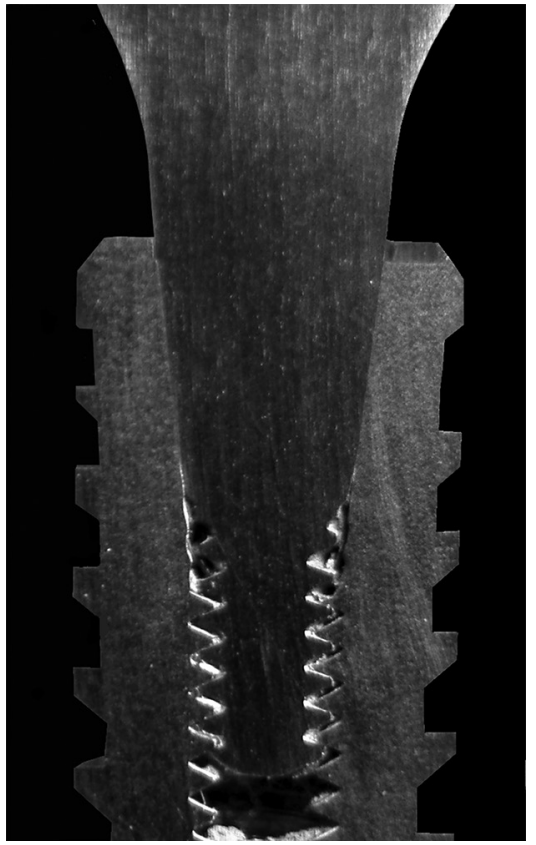

Figure 3. Image of a sample after embedment in resin and central longitudinal section.

(p1, p2, p3 and p4), as shown in Figure 5. These measurements were performed at a magnification of $500 \mathrm{x}$ and were obtained with the aid of Image Tool 3.0 for Windows (University of Texas Health Science Center, San Antonio, USA).

The measurements were taken independently by two researchers (SG and BD) and repeated three times for each reference point for each group. The mean values were considered in the evaluation.

The statistical analyses were performed using one-way analysis of variance (ANOVA) to determine the differences between the four groups, with the
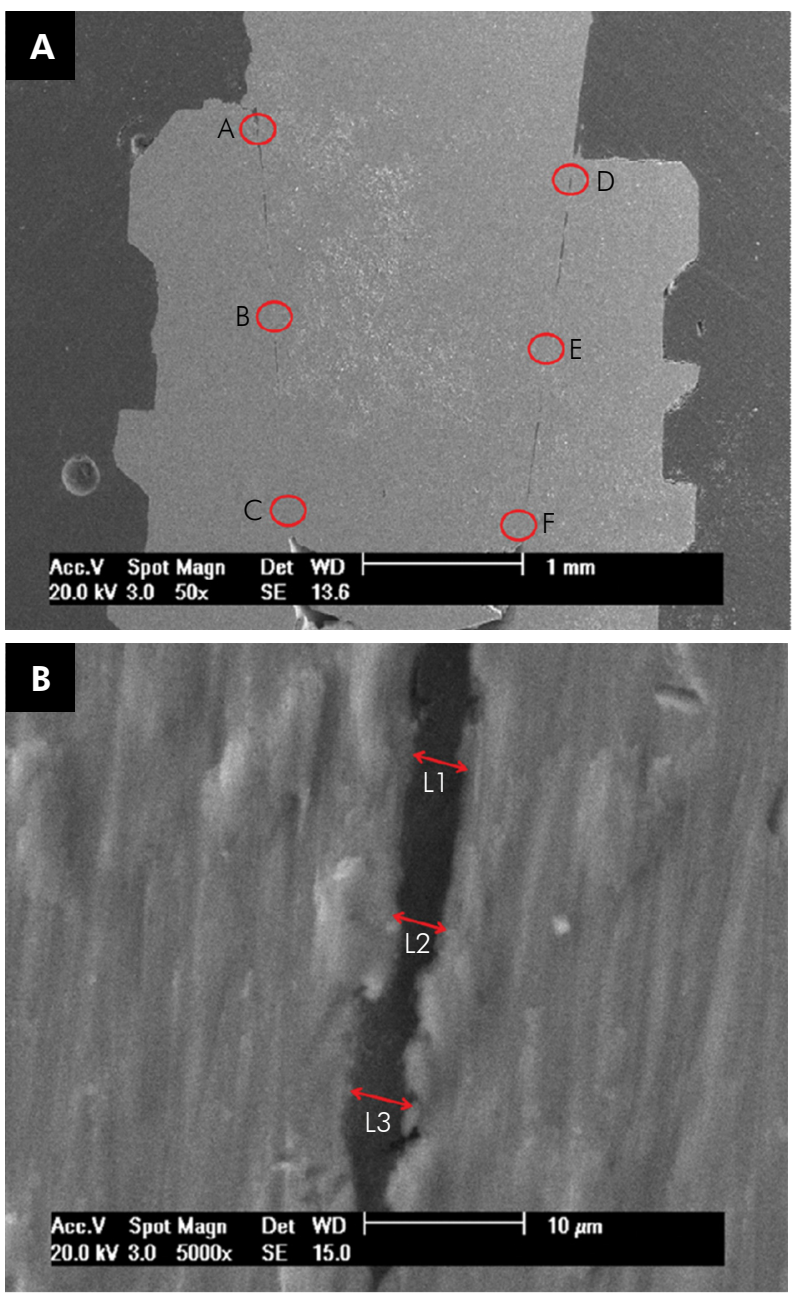

Figure 4. Image of the areas established for the measurements of the gaps in each sample.

subsequent analysis of the results by Tukey's test. All analyses were performed using Statistic Software (StatSoft, Inc., Tulsa, USA.), version 7.0. T-tests were 


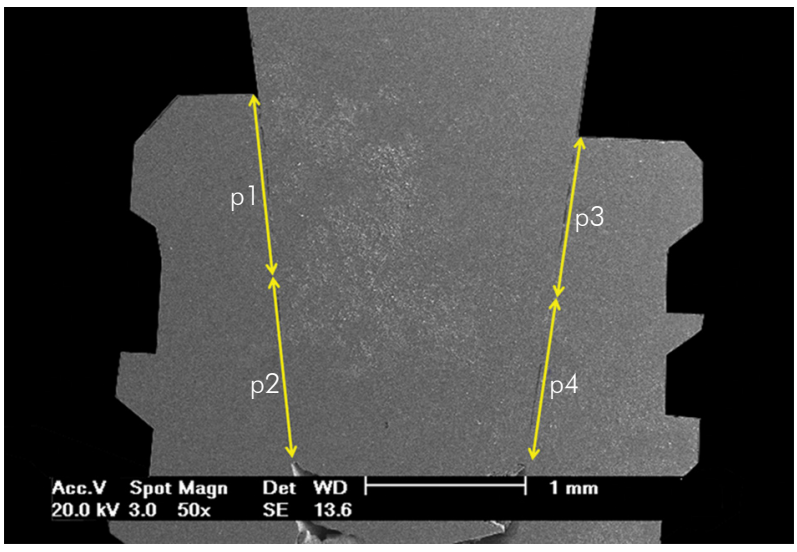

Figure 5. Scheme of the locations (positions) defined for the measurements of the linear contact between abutment and implant.

applied to verify the differences between the groups (significance set as $\alpha=0.05$ ). It was determined that six samples from each group would generate a $95 \%$ confidence interval (G3Power, Düsseldorf, Germany); however, 10 samples were obtained for each situation in order to increase the level of significance.

\section{Results}

The mean values for the misfits in the determined positions after four torque levels (g1, g2, g3 and g4) are expressed in micrometers $(\mu \mathrm{m})$ (Table 1$)$. As shown in the table, all no-contact values between the implant and abutment walls were larger, sometimes by more than $10 \mu \mathrm{m}$, when the $25 \mathrm{Ncm}$ load was applied, decreasing significantly when torque values were higher. Statistical analyses of the gaps between implant and abutment were performed only for positions $\mathrm{A}, \mathrm{B}, \mathrm{D}$ and $\mathrm{E}$ because positions $\mathrm{C}$ and $F$ had a zero value in all groups. Then, an overall mean value was calculated for each group for all four positions, and the one-way ANOVA, followed by the Tukey's test, revealed significant differences between the groups. The statistical analysis is shown in Table 2 and a boxplot with the overall mean gap is displayed in Figure 6. The comparison of data between groups reveals larger differences (less gap) in groups g3 and g4.

The measurements of the points of contact between abutment and implant in the four predefined positions determined by the schematic lines (p1, p2, p3 and p4) are presented as percentages of contact (Table 3 ).

\section{Discussion}

The implant-abutment interface has been reported to be a significant factor in terms of load transfer, adverse biological responses, and technical complications. In implants with conical internal connections, the contact of the implant-abutment junction determines a successful fit and is directly related to the preload attained during torque application. In this study, a gradual decrease in the gap between implant and abutment was observed when torque was increased. The differences between the groups were statistically significant, primarily in the four more cervical positions, and all of the contacts in all groups were complete.

During abutment screw tightening, the applied torque develops a tensile force within the screw stem, generating a compressive clamping force between implant and abutment. In designs such as the butt-joint implant/abutment connection, in which the abutment screw alone is the element that is primarily responsible for keeping the implant and the abutment assembled, maintenance of the preload is extremely crucial. In such designs, the most probable causes of screw loosening are excessive bending of the screw joint and settling effects that arise from micromovements in the implant-abutment interface. ${ }^{14}$

To avoid the potential clinical failure of screw joints, it is essential that either the clamping force be maximized or the joint separating forces be maintained below the clamping force ${ }^{18}$ However, in Morse taper connections, form lock and friction are the basic principles, and this mechanism, referred to as positive or geometric locking, is assumed to be responsible for protecting abutment threads from excessive functional load. ${ }^{19}$ Differently from butt-joint designs, the reduced micromovement of the Morse taper interface provides superior strength and joint stability. ${ }^{20,21}$ In this study, all abutments were sound and stably in place without any sign of loosening regardless of the applied torque value. The Morse taper indisputably carried most of the applied load and protected abutment screw threads from overloading. This observation has also been confirmed by the results of studies that have found that removal torque values of abutments indicate that friction plays a decisive role in maintenance of the preload. ${ }^{22}$ 
Table 1. Mean misfit values at the determined positions after the application of the four torque levels (expressed in $\mu \mathrm{m}$ ).

\begin{tabular}{lcccc}
\hline Position & Group g1 & Group g2 & Group g3 & Group g4 \\
\hline A & $10.1 \pm 0.50$ & $10.3 \pm 0.67$ & $2.9 \pm 0.30$ & $0.9 \pm 0.27$ \\
B & $7.7 \pm 0.46$ & $7.3 \pm 1.26$ & $1.6 \pm 0.36$ & 0 \\
C & 0 & 0 & 0 & 0 \\
D & $10.4 \pm 0.68$ & $10.7 \pm 0.75$ & $2.3 \pm 0.78$ & $0.4 \pm 0.25$ \\
E & $7.1 \pm 0.56$ & $6.1 \pm 1.16$ & $1.3 \pm 0.43$ & 0 \\
F & 0 & 0 & 0 & 0 \\
\hline
\end{tabular}

Table 2. Results of the ANOVA and Tukey post-hoc tests.

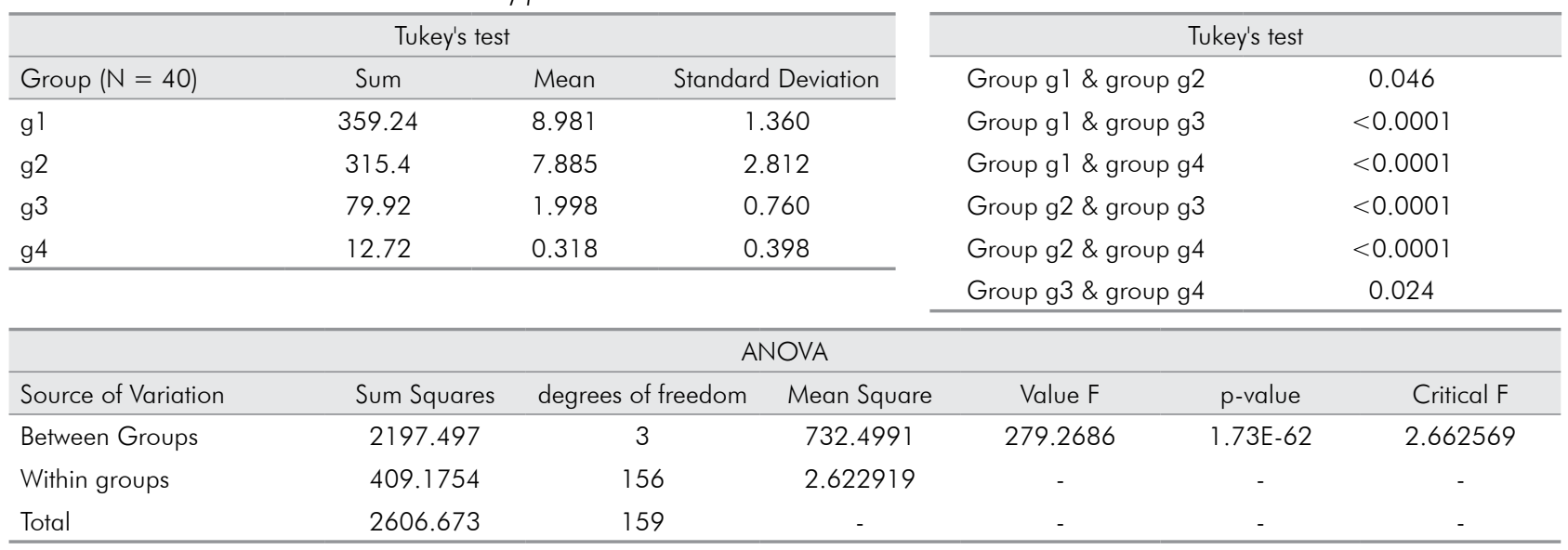

Table 3. Measurements of the areas of linear contact between the internal walls of the abutments and implants at the preset positions (expressed in percentages).

\begin{tabular}{lcccc}
\hline & Group g1 & Group g2 & Group g3 & Group g4 \\
\hline Position p1 & 0 & 0 & 28.13 & 82.5 \\
Position p2 & 64.38 & 96.25 & 100 & 100 \\
Position p3 & 0 & 0 & 20 & 90.63 \\
Position p4 & 61.25 & 98.75 & 100 & 100 \\
\hline
\end{tabular}

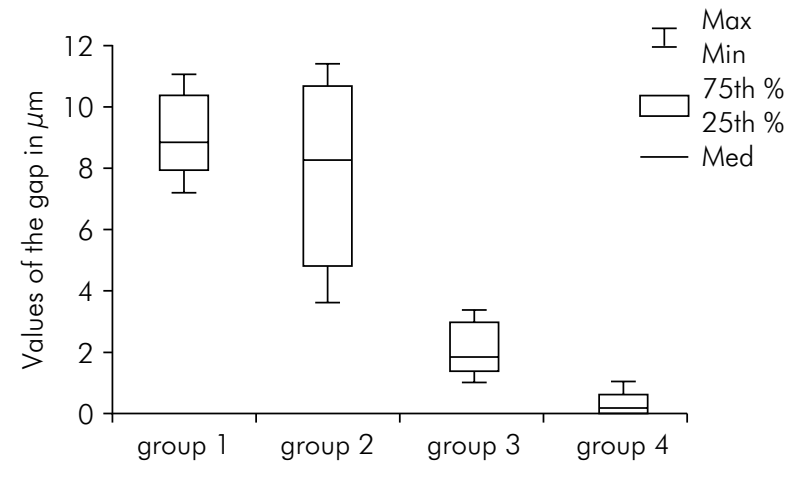

Figure 6. Boxplot of the overall mean gap for each group for the four positions (A, B, D and E).
A hand-held ratchet-type torque wrench with no actual release mechanism was used. The wrench was inserted into a string-activated sleeve using a present scale, and force was applied until the desired torque was visually achieved. A recent study on the accuracy of torque-limiting devices has shown that torque devices deliver consistent torque outputs within $10 \%$ of their preset target values. ${ }^{23}$ Therefore, in the present study, a digital computed torque controller was used to ensure that all of the abutments were tightened to the torque values that were determined for each group. 
Another reason to examine the maximum setting and contact between the parts (i.e., abutment and implant) to seal or reduce the space in which bacteria and fluids can enter and exit the inner chamber of the implant is that such spaces create a location for potential bacterial colonization. In 2014, D'Ercole et al. ${ }^{24}$ performed an in vitro study on bacterial leakage in Morse cone internal connection implants using different torque values $(20$ $\mathrm{Ncm}, 30 \mathrm{Ncm}$, and $40 \mathrm{Ncm}$ ). Their results revealed bacterial contamination at $20 \mathrm{Ncm}$ and $30 \mathrm{Ncm}$, but no contamination at $40 \mathrm{Ncm}$. These results demonstrate that increased insertion torque values in Morse cone connections reduce bacterial leakage. These results support our hypothesis and our finding that torque values below $35 \mathrm{Ncm}$ (in the present study 25 and $30 \mathrm{Ncm}$ ) reduce the amount of contact between the abutment and implant walls, resulting, consequently, in less effective bacterial seals. Until now, there has been no consensus about the clinical impact of the presence or not of periodontal pathogens around the implant connection, nor about the real importance of the microgap for bacterial infection. ${ }^{6,25}$

Recently, in a systematic review of the literature, Schmitt et al. ${ }^{25}$ compared conical and nonconical implant-abutment connection systems in terms of their in vitro and in vivo performances. In vitro studies indicate that conical and nonconical abutments exhibited sufficient resistance to the maximal bending forces and fatigue loading. However, conical abutments were superior in terms of sealing, microgap formation, torque maintenance, and abutment stability. In vivo studies (in humans and animals) indicate that conical and nonconical systems were comparable in terms of implant success and survival rates, and lower marginal bone loss around conical connection implants was observed in most cases. This review indicated that implant systems that use conical implant-abutment connections provide better

\section{References}

1. García-Bellosta S, Bravo M, Subirá C, Echeverría JJ. Retrospective study of the long-term survival of 980 implants placed in a periodontal practice. Int J Oral Maxillofac Implants. 2010;25(3):613-9.

2. Pjetursson BE, Brägger U, Lang NP, Zwahlen M. Comparison of survival and complication rates of tooth-supported fixed dental prostheses (FDPs) and implant-supported FDPs and single results in terms of abutment fit, stability, and sealing. These design features could lead to improvements compared to nonconical connection systems. ${ }^{26}$

Hence, using the appropriate torque in conical internal connection implants and decreasing the gap immediately after the insertion of the abutment can reduce the possibility of any bacterial contamination that occurs simultaneously with the loading of the implant at the time of prosthesis placement, because these factors, together, depending on the patient's sensitivity threshold, could cause trauma to peri-implant tissues.

There were some limitations in this study. During the clinical application of torque, some load is transmitted to the bone and, in this model, the implants were embedded in a rigid resin base, conveying the full amount of programmed torque. Furthermore, during the clinical procedure, torque wrenches do not have the same precision as the torque apparatus used for the insertion of abutments in this study. It would be interesting to conduct other studies that more adequately simulate these conditions, in addition to verifying whether a higher torque on pillars generates stress on the peri-implant bone tissue.

\section{Conclusion}

With a higher torque, the linear area of contact between implant and abutment increases, reducing the gap between the pieces. The results obtained in this study, despite their limitations, indicate that $35 \mathrm{Ncm}$ was the best torque value for this type of conical internal connection (cone with $11^{\circ}$ ).

\section{Acknowledgments}

The authors gratefully acknowledge Implacil DeBortoli - Produtos Odontológicos Ltda., for the supply of the test components used in this study.

crowns (SCs). Clin Oral Implants Res. 2007;18(Suppl 3):97-113. doi:10.1111/j.1600-0501.2007.01439.x

3. Jung RE, Pjetursson BE, Glauser R, Zembic A, Zwahlen M, Lang NP. A systematic review of the 5-year survival and complication rates of implant-supported single crowns. Clin Oral Implants Res 2008;19(2):119-30. doi:10.1111/j.1600-0501.2007.01453.x 
4. Michalakis KX, Hirayama H, Garefis PD. Cement-retained versus screw-retained implant restorations: a critical review. Int J Oral Maxillofac Implants. 2003;18(5):719-28.

5. Jansen VK, Conrads G, Richter EJ. Microbial leakage and marginal fit of the implant-abutment interface. Int J Oral Maxillofac Implants. 1997;12(4):527-40.

6. Quirynen M, De Soete M, van Steenberghe D. Infectious risks for oral implants: a review of the literature. Clin Oral Implants Res. 2002;13(1):1-19. doi:10.1034/j.1600-0501.2002.130101.x

7. Burguete RL, Johns RB, King T, Patterson EA. Tightening characteristics for screwed joints in osseointegrated dental implants. J Prosthet Dent. 1994;71(:6)592-9. doi:10.1016/0022-3913(94)90443-X

8. Listgarten MA, Lang NP, Schroeder HE, Schroeder A. Periodontal tissues and their counterparts around endosseous implants. Clin Oral Implants Res. 1991;2(3):1-19. doi:10.1034/j.1600-0501.1991.020309.x. Corrected and republished with original paging, article orginally printed in Clin Oral Implants Res. 1991;2(1):1-19. doi:10.1034/j.1600-0501.1991.020101.x

9. Gratton DG, Aquilino SA, Stanford CM. Micromotion and dynamic fatigue properties of the dental implant-abutment interface. J Prosthet Dent. 2001;85(1):47-52. doi:10.1067/mpr.2001.112796

10. Carotenuto G, Palumbo M, Zarone F, Nicolais L. Characterization of the interface between prefabricated gold copings and cast dental alloy in implant restorations. Clin Oral Implants Res. 1999;10(2):131-8. doi:10.1034/j.1600-0501.1999.100207.x

11. Tzenakis GK, Nagy WW, Fournelle RA, Dhuru VB. The effect of repeated torque and salivary contamination on the preload of slotted gold implant prosthetic screws. J Prosthet Dent. 2002;88(2):183-91. doi:10.1067/mpr.2002.127604

12. Haack JE, Sakaguchi RL, Sun T, Coffey JP. Elongation and preload stress in dental implant abutment screws. Int J Oral Maxillofac Implants. 1995;10(5):529-36.

13. Cibirka RM, Nelson SK, Lang BR, Rueggeberg FA. Examination of the implant-abutment interface after fatigue testing. J Prosthet Dent. 2001;85(3):268-75. doi:10.1067/mpr.2001.114266

14. Jörnéus L, Jemt T, Carlsson L. Loads and designs of screw joints for single crowns supported by osseointegrated implants. Int J Oral Maxillofac Implants. 1992;7(3):353-9.

15. Mangano FG, Shibli JA, Sammons RL, Iaculli F, Piattelli A, Mangano C. Short (8-mm) locking-taper implants supporting single crowns in posterior region: a prospective clinical study with 1-to 10-years of follow-up. Clin Oral Implants Res. 2014;25(8):933-40. doi:10.1111/clr.12181

16. Mangano C, Mangano F, Shibli JA, Tettamanti L, Figliuzzi M, d'Avila S, et al. Prospective evaluation of 2,549 Morse taper connection implants: 1- to 6-year data. J Periodontol. 2011;82(1):52-61. doi:10.1902/jop.2010.100243

17. Breeding LC, Dixon DL, Nelson EW, Tietge JD. Torque required to loosen single-tooth implant abutment screws before and after simulated function. Int J Prosthodont. 1993;6(5):435-9.

18. McGlumphy EA, Mendel DA, Holloway JA. Implant screw mechanics. Dent Clin North Am. 1998;42(1):71-89.

19. Merz BR, Hunenbart S, Belser UC. Mechanics of the implant-abutment connection: an 8-degree taper compared to a butt joint connection. Int J Oral Maxillofac Implants. 2000;15(4):519-26.

20. Sutter F, Weingart D, Mundwiler U, Sutter FJ, Asikainen P. ITI implants in combination with bone grafts: design and biomechanical aspects. Clin Oral Implants Res. 1994;5(3):164-72. doi:10.1034/j.1600-0501.1994.050307.x

21. Gehrke SA, Pereira FA. Changes in the abutment-implant interface in Morse taper implant connections after mechanical cycling: a pilot study. Int J Oral Maxillofac Implants. 2014;29(4):791-7. doi:10.11607/jomi.3113

22. Gehrke SA, De Carvalho Serra R. Load fatigue performance of conical implant-abutment connection: effect of torque level and interface junction. Minerva Stomatol. 2015;64(1):1-7.

23. Standlee JP, Caputo AA, Chwu MY, Sun TT. Accuracy of mechanical torque-limiting devices for implants. Int J Oral Maxillofac Implants. 2002;17(2):220-4.

24. D'Ercole S, Tripodi D, Ravera L, Perrotti V, Piattelli A, Iezzi G. Bacterial leakage in morse cone internal connection implants using different torque values: an in vitro study. Implant Dent. 2014;23(2):175-9. doi:10.1097/ID.0000000000000044

25. Shibli JA, Ivanovski S, Park YB, Alarcon M, Cheung KM, Duncan W, et al. Group D. Consensus report. Implants--peri-implant (hard and soft tissue) interactions in health and disease: the impact of explosion of implant manufacturers. J Int Acad Periodontol. 2015;17(1 Suppl):71-3.

26. Schmitt CM, Nogueira-Filho G, Tenenbaum HC, Lai JY, Brito C, Döring H, et al. Performance of conical abutment (Morse Taper) connection implants: a systematic review. J Biomed Mater Res A. 2014;102(2):552-74. doi:10.1002/jbm.a.34709 